\title{
Early manifestations of replicative aging in the yeast Saccharomyces cerevisiae
}

\author{
Maksim I. Sorokin ${ }^{1,3}$, Dmitry A. Knorre ${ }^{2,3}$, and Fedor F. Severin ${ }^{2,3, *}$ \\ ${ }^{1}$ Faculty of Bioengineering and Bioinformatics, Moscow State University, Vorobyevy Gory 1, Moscow, Russia \\ ${ }^{2}$ Belozersky Institute of Physico-Chemical Biology, Moscow State University, Vorobyevy Gory 1, Moscow, Russia \\ ${ }^{3}$ Institute of Mitoengineering, Moscow State University, Vorobyevy Gory 1, Moscow, Russia \\ * Corresponding Author: Fedor F. Severin, Belozersky Institute of Physico-Chemical Biology, Moscow State University, Vorobyevy \\ Gory 1; Moscow 119992, Russia; Tel.: +7-495-9393107; Fax: +7-495-9393181; E-mail: severin@belozersky.msu.ru
}

\begin{abstract}
The yeast Saccharomyces cerevisiae is successfully used as a model organism to find genes responsible for lifespan control of higher organisms. As functional decline of higher eukaryotes can start as early as one quarter of the average lifespan, we asked whether $S$. cerevisiae can be used to model this manifestation of aging. While the average replicative lifespan of $S$. cerevisiae mother cells ranges between 15 and $\mathbf{3 0}$ division cycles, we found that resistances to certain stresses start to decrease much earlier. Looking into the mechanism, we found that knockouts of genes responsible for mitochondriato-nucleus (retrograde) signaling, RTG1 or RTG3, significantly decrease the resistance of cells that generated more than four daughters, but not of the younger ones. We also found that even young mother cells frequently contain mitochondria with heterogeneous transmembrane potential and that the percentage of such cells correlates with replicative age. Together, these facts suggest that retrograde signaling starts to malfunction in relatively young cells, leading to accumulation of heterogeneous mitochondria within one cell. The latter may further contribute to a decline in stress resistances.
\end{abstract}

\author{
doi: $10.15698 /$ mic2014.01.122 \\ Received originally: 22.11 .2013 ; \\ in revised form: 10.12.2013, \\ Accepted 12.12.2013 \\ Published 06.01.2014.
}

Keywords: yeast, aging, stress resistance, retrograde signaling.

\section{INTRODUCTION}

The budding yeast Saccharomyces cerevisiae is an example of a unicellular organism with markedly asymmetrical division: newly emerged daughter cells are normally significantly smaller than the mothers (see [1]). However, the asymmetry is not limited to the differences in volume: mother-to-daughter transport of a specific set of mRNAs prevents mating type switching by repression of the $\mathrm{HO}$ promoter in the daughter cells [2]. Further, it was shown that carbonylated or misfolded proteins and extrachromosomal rDNA circles [3] are retained in the mother cells. Recently, we showed that such transport is necessary to prevent high stress susceptibility of the daughter cells [4]. At the same time, multiple rounds of asymmetrical divisions result in subsequent decrease in viability in replicatively old cells. As a result, the chance of a spontaneous death of the yeast cell increases with each division cycle after production of approximately 15 buds $[5,6]$. One of the most pronounced consequences of asymmetrical redistri- bution of cytoplasmic contents appears to be the mitochondrial morphology. In yeast, abnormal morphology of the mitochondrial network and increased reactive oxygen species production can be observed already after 6-8 divisions [7]. The latter is not surprising because the mother/daughter redistribution of mitochondria is not random: the mother cell tends to retain mitochondria with higher superoxide level [8], while mitochondria with intact aconitase (a Fe-S cluster-containing enzyme that is sensitive to ROS) are preferentially transported to the bud [9].

Here we report a number of changes in cellular physiology (i.e. a decrease in stress resistances) that occur even earlier than 6-8 cell divisions. We also found that the probability of harboring a mitochondrial fragment with significantly different transmembrane potential than in the rest of the mitochondrial network within same cell increases with each cell cycle. These early age-dependent changes might significantly affect the stress resistances of the cells. 


\section{RESULTS}

\section{Stress resistances change early during replicative aging}

First, to test the age-dependence of stress resistances, exponentially growing yeast cells were subjected to a number of treatments (Table 1 ) and then stained with propidium iodide (PI) to visualize dead cells and with calcofluor white (CW) to visualize birth and bud scars. Then we counted the scars for each dead and live cell and calculated the percentage of $\mathrm{PI}$ positive cells for each aging class, where age $=1$ corresponds to virgin daughter cells (with birth scars only), age $=2$ corresponds to mother cells (with one birth scar and one bud scar), etc. As the proportion of cells with more than four scars did not exceed $6 \%$ of the total (Figure S1), we pooled them into one group $(\geq 5)$ and analyzed it as a single aging class. We found that in case of heat shock the dead/alive cell ratios for different aging classes were statistically different (Figure 1A). The same results were obtained for hyperosmotic (Figure $1 \mathrm{~A}$ ) and acidic stresses (Figure S2). However, in the case of oxidative stress (menadione) and for stresses induced by high concentrations of ethanol or butanol, there were no statistically significant differences (Figure S2).

Virgin daughter cells have some unique properties. In particular, daughter cells have increased duration of G1 phase of cell cycle compared to mother cells [10] and demonstrate significantly lower resistances to acetic acid stress and heat shock [4]. Therefore, we excluded the daughter cells (age $=1$ ) from the calculations and performed the statistical Kruskal-Wallis test for the mother cells only. It was found that for heat shock and hyperosmotic stress the $p$ value is below 0.01 (Figure 1A), whereas for acetic acid stress the $p$ value was 0.29 (Figure S2).
TABLE 1. Types of stresses used in this study.

\begin{tabular}{lll}
\hline Type of stress & $\begin{array}{l}\text { Chemical agent } \\
\text { (final concentration) }\end{array}$ & Duration \\
\hline Osmotic stress & $\mathrm{NaCl}(2.5 \mathrm{M})$ & $30 \mathrm{~min}$ \\
\hline \multirow{2}{*}{ Alcohol stress } & Ethanol (20\%) & $60 \mathrm{~min}$ \\
\cline { 2 - 3 } & Butanol (1\%) & 16 hours \\
\hline Heat shock $\left(47^{\circ} \mathrm{C}\right)$ & - & 30 min \\
\hline Oxidative stress & Menadione $(1 \mathrm{mM})$ & 2 hours \\
\hline Acidic stress & $\begin{array}{l}\text { Acetic acid }(180 \mathrm{mM}, \\
\text { media } \mathrm{pH} 3.5)\end{array}$ & 2 hours \\
\hline
\end{tabular}

Obviously the ability to extrude propidium iodide is not the only criterion of stress resistance. Another is the ability to start growing after the return to stress-free conditions. Thus, we decided to test whether this ability depends on replicative age. To do that, we synchronized yeast cells with nocodazole and stained the cell walls with FITC-ConA (Concanavalin A labeled with green fluorescent dye). FITCConA irreversibly binds to the cell thus allowing to distinguish between the old cells (stained) and the newly emerged (unstained ones). Then the cells were subjected to a mild stress: $+42^{\circ} \mathrm{C}$ for 30 minutes. After removal of the stress, we incubated the cells at $30^{\circ} \mathrm{C}$ for 90 minutes, stained them with calcofluor white to visualize ages, and measured the sizes of the newly formed (FITC-ConA free) buds (Figure 1B). It appeared that cells with two scars have
A

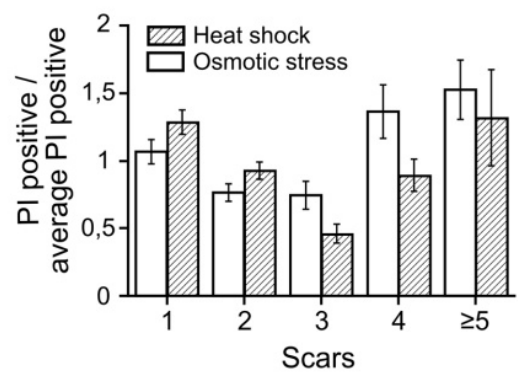

C

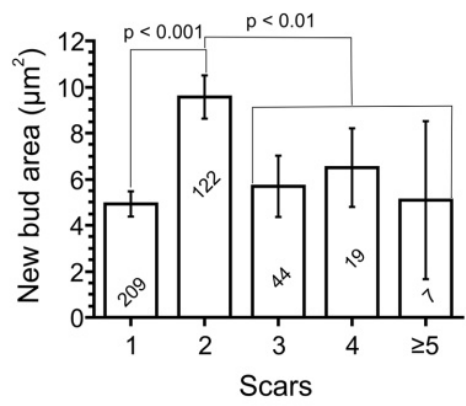

B

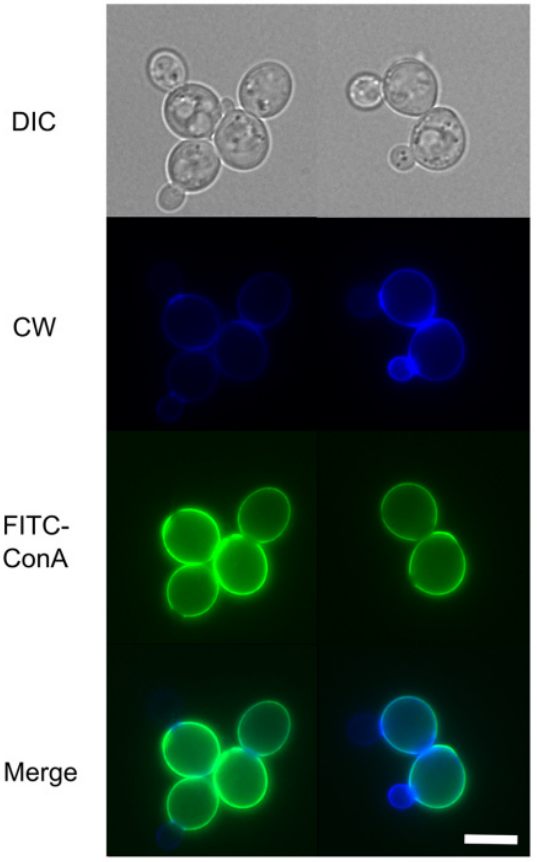

FIGURE 1: Stress resistances and regrowth of yeast cells depend on their replicative age. (A) The data are presented as percentages of dead cells in a particular aging class divided by the average percentages of dead cells in this experiment. Values higher than one show that the percentage of dead cell in this aging class is above average, and values below one represent the relatively resistant aging classes. $p<$ 0.01 for all treatments, Kruskal-Wallis test. (B, C) Microscopy and quantification of regrowth. In $\mathrm{C}$ the exact numbers of cells analyzed are shown in each column. Bar $=5 \mu \mathrm{m}$. 
larger buds compared to the other age classes (Figure 1C).

Together these data support the idea that the stress resistances of yeast cells which represent the major part of the population (ages 1-5) vary depending on their replicative age.

\section{Mitochondrial function and stress resistance during repli- cative aging}

What determines these early age-dependent changes in the stress resistances? It is known that mitochondrial morphology of the mother cells starts to change already after five or six cell cycles [7]. Thus, we decided to look in more detail at age-dependent changes in mitochondria. We used yeast cells expressing mitochondria-targeted GFP [11] and stained them with tetramethylrhodamine (TMR). TMR is a lipophilic cation that accumulates in mitochondria depending on their $\Delta \Psi$. We noticed that the mother cells have much higher levels of heterogeneity within a cell than the daughters and that the level of heterogeneity positively correlates with replicative age (Figures 2 A, B).

What are the possible links between the mitochondrial heterogeneity and the stress resistances? Malfunctioning mitochondria in yeast induce specific transcriptional changes in the nuclei that act to normalize the mitochondrial activities. Therefore, our finding that aging yeast cells contain heterogeneous mitochondria (meaning that some of them might be not in optimal conditions) may reflect the fact that this signaling pathway in such cells is compromised. The mitochondria-to-nucleus signaling is driven by transcription factors of the retrograde pathway: RTG1, $R T G 2$, and RTG3 [12]. We found that the deletion of $r \operatorname{tg} 1$ or rtg3 affects old cells but not the young ones when subjected to severe heat stress ( 30 minutes at $47^{\circ} \mathrm{C}$, Figure $2 \mathrm{C}$ ). This indicates that cells with replicative age higher than four are more reliant on retrograde signaling.

We also compared the effects of preconditioning on the stress responses of cells of different ages. It appeared that the preconditioning increased survival of the young cells to such an extent, that proportion of PI-positive cells became similar between the cells with 1 to 4 scars (Figure $2 \mathrm{D})$. The viability of the preconditioned cells with $\geq 5$ scars also seemed to be higher than in control. However, the proportion of PI-positive cells of this aging class appeared to be different from the one for younger ages (Figure 2D). This supports the idea that in the old cells the ability to adapt to a changing environment is diminished.

Does this mean that the mitochondrial heterogeneity is a sign of a general decline of the cell? Recently we showed that differentiation of yeast cells requires two subpopulations of mitochondria [13]. This result implies that the ability of cells to differentiate in response to environmental signals increases with replicative age. To test this, we induced meiosis in diploid cells by plating them on solid medium containing $2 \%$ potassium acetate. As predicted, it appeared that the ability of cells to form spores positively correlates with age (Figure 3); at the same time, the diploid cells show similar stress resistance profile as haploids cell (Figure S3). It should be noted, however, that the latter
FIGURE 2: (A) Mitochondrial heterogeneity within a cell increases with age. Representative images of cells with uniform and heterogeneous subpopulations of mitochondria. Cells expressing mitochondrial GFP (mitoGFP) were stained with tetramethylrhodamine (TMR) and calcofluor white (CW). Bar $=5 \mu \mathrm{m}$. (B) Quantification of the results from (A). 114 cells were analyzed from 3 independent experiments. The difference between actual and expected (average proportion of cells with heterogeneous potential among the whole population) values is significant according to the chi-squared test $(p<0.05)$. Positive correlation is also significant according to Kendall's $(\mathrm{p}$-value $=0.05$, tau $=0.8)$ and Spearman's ( $\mathrm{p}$-value $=$ 0.037 , rho $=0.9$ ) tests. (C) Knockouts of retrograde signaling genes decrease the survival of yeast cells with replicative ages above four. Cell were subjected to heat shock and then stained with propidium iodide (PI) and calcofluor white (see Materials and methods). The scars were calculated for each individual cell. The percentage of PI-positive (dead) cells was plotted as a function of replicative age (numbers of scars). ${ }^{*}$ indicates $p<0.05$ when compared to wt, Wilcoxon test. (D) Preconditioning decreases the difference in heat shock resistance between daughter cells and young mother cells. Yeast cells were incubated for $30 \mathrm{~min}$ at $37^{\circ} \mathrm{C}$ and then stressed with heat shock $\left(47^{\circ} \mathrm{C}\right)$. Then the cells were stained with propidium iodide $(\mathrm{PI})$ and calcofluor white (see Materials and methods). The percentages of PI-positive (dead) cells were plotted as a function of replicative age (numbers of scars). ${ }^{*}$ indicates $p<0.01, \#$ indicates $p=0.057$.
A

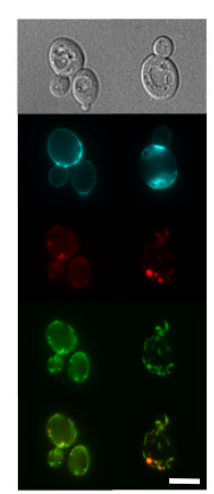

DIC
CW
TMR
mtGFP
Merge

C

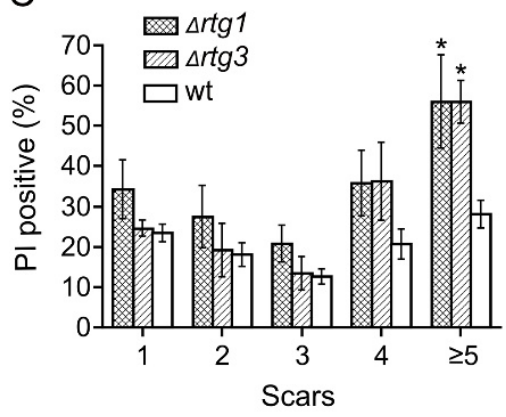

B

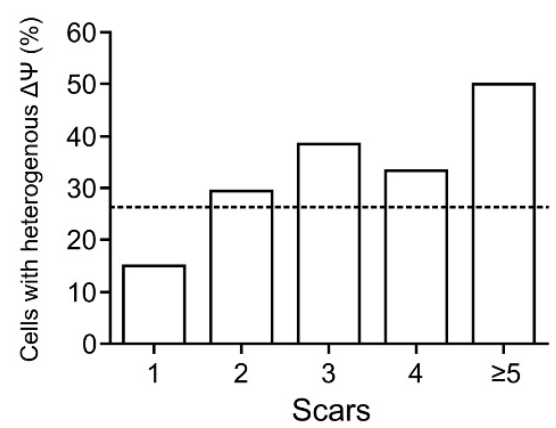

D $\square$ wt (precondition)

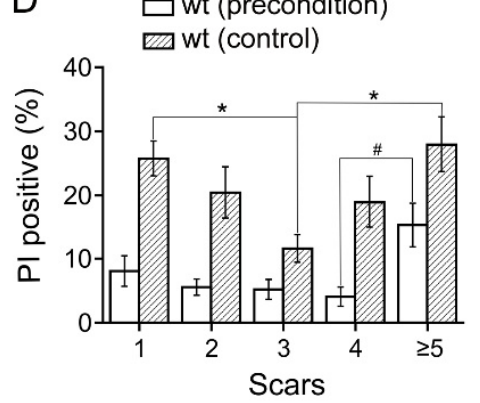


effect could be due to correlation of sporulation efficiency and cell size [14], which also strongly correlates with cell age (Figure S4).

\section{DISCUSSION}

Our data suggest that the response to environmental challenges of yeast starts to change early during their replicative aging. In particular, these changes lead to a decreased resistance to certain stresses of the cells with 4-5 scars. This implies that under natural (as opposed to laboratory) conditions the cells are unlikely to reach replicative age of twenty or thirty. Does this mean that most of the works on yeast replicative aging (which were conducted under laboratory conditions) were studying laboratory artifacts? It was found that similar groups of genes regulate replicative lifespan in yeast and longevity in worms and mice (histone deacetylases, antioxidant enzymes, etc., see for review [15]). At the same time, similarly to yeast, functional decline of humans also starts at relatively early age. For example, a decrease in the number of immune T-cells in humans starts at the age of 15 years [16]. Therefore, our data suggest that yeast can serve as a model to study not only lifespan-regulating mechanisms, but also the mechanisms of early age-associated functional decline. Interestingly, fission yeast display similar aging phenotype. Recently, it was reported that while $S$. pombe does not seem to age replicatively under standard laboratory conditions, stresses force them to do so [17].

Our data also show that not all stress resistances show sharp age-dependence. Moreover, the ability for spore formation seems to increase during early aging. In other words, early aging in yeast displays features of both regular aging and differentiation. At the same time, it is well known that heterogeneity of individual cells in clonal microbial populations helps them to survive in randomly changing environment. For instance, a small fraction of bacterial cells (persisters) show slower growth rate and, at the same time, increased antibiotic resistance [18]. Early age-dependent differentiation of yeast cells has also been already reported. In the stationary phase of growth, $S$. cerevisiae forms two types of cells: quiescent and nonqui-
A

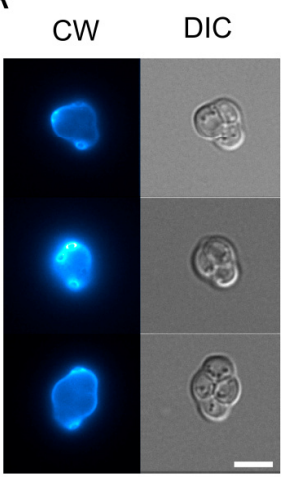

B

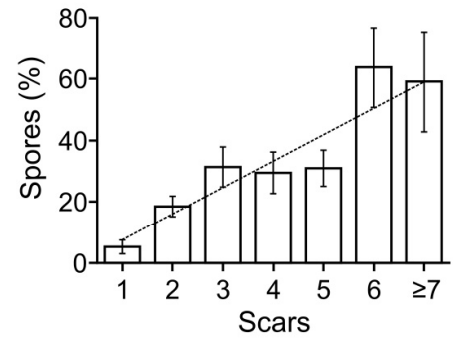

FIGURE 3: Sporulation ability is positively correlated with the number of completed cell cycles. (A) Representative images of yeast tetrads stained with calcofluor white $(\mathrm{CW})$ and visualized under differential interference contrast (DIC). Bar $=5 \mu \mathrm{m}$. (B) Quantification of results. 1183 cells analyzed from 8 separate experiments. Kendall's tau $=0.54$, Spearman's rho $=0.65, p<$ 0.001 both tests.

escent $[19,20]$. Quiescent cells are represented mainly by virgin daughters; they are arrested in the G1 phase of the cell cycle and have a higher chance to survive in the stationary phase. The nonquiescent cells are continuing to proliferate. Our data suggest that such differentiation is more complex than simply mother-daughter differences. Possibly, there is a distinct number (higher than two) of aging classes of cells, with each class showing a unique set of resistances to harsh conditions.

\section{MATERIALS AND METHODS}

Strains and growth conditions

In this study, we used strains of W303 genetic background strain (Table 2). If not indicated, exponentially growing yeast cells were prepared as following: prior to the treatments the cells were grown overnight at $30^{\circ} \mathrm{C}$ on solid YPD medium prepared according to [21] and transferred in liquid YPD for 3.5-4 hours until the optical density $\left(O D^{550}\right)$ of the suspension reached $0.2\left(4 \times 10^{6}\right.$ cells per $\left.\mathrm{ml}\right)$.

TABLE 2. Yeast strains used in this study.

\begin{tabular}{lll}
\hline Strain & Genotype & Source or reference \\
\hline W303 & MATa ade2-101 his3-11 trp1-1 ura3-52 can1-100 leu2-3 & [22] \\
\hline W303 (2n) & $\begin{array}{l}\text { ade2-101/ade2-101 his3-11/his3-11 trp1-1/trp1-1 ura3-52/ura3-52 can1- } \\
100 / \text { can1-100 leu2-3/leu2-3 }\end{array}$ & $\begin{array}{l}\text { this study, mating W303 } \\
\text { with isogenic mat alpha } \\
\text { strain }\end{array}$ \\
\hline Mrtg1 & MATa ade2-101 his3-11 trp1-1 ura3-52 can1-100 leu2-3 rtg1::KanMX4 & {$[13]$} \\
\hline Mrtg3 & MATa ade2-101 his3-11 trp1-1 ura3-52 can1-100 leu2-3 rtg3::KanMX4 & [13]
\end{tabular}




\section{Stress induction}

Cell suspensions in liquid YPD were subjected to various types of stresses: $2.5 \mathrm{M} \mathrm{NaCl}$ for 30 minutes, $20 \%$ ethanol for 1 hour, $1 \%$ butanol for 16 hours, heat shock $\left(47^{\circ} \mathrm{C}\right)$ for 30 minutes, 1 $\mathrm{mM}$ menadione for 2 hours, or $180 \mathrm{mM}$ acetic acid ( $\mathrm{pH}$ of the medium was set to 3.5) for 2 hours. The types of stresses used in this study are summarized in Table 1 . Incubation of the cells for 30 minutes at $37^{\circ} \mathrm{C}$ was used as preconditioning for heat shock. Sporulation of diploid W303 cells was induced on solid potassium acetate-containing medium ( $2 \%$ potassium acetate, $2 \%$ agar) for 3 days.

\section{New bud formation}

The cells were synchronized with nocodazole $(10 \mu \mathrm{g} / \mathrm{ml})$, washed 4 times with YP, then moved to YPD containing FITCconjugated Concanavalin A (FITC-ConA) and incubated at $30^{\circ} \mathrm{C}$ for 10 minutes and then at $42^{\circ} \mathrm{C}$ for 30 minutes. Then the cells were washed 2 times with YPD and incubated at $30^{\circ} \mathrm{C}$ in YPD for 90 minutes. After 90 minutes, the cells were transferred to YP media containing calcofluor white, as described in the Microscopy section.

\section{Microscopy}

After the stresses the cells were washed with YP containing Propidium lodide $(\mathrm{Pl}, 1 \mu \mathrm{g} / \mathrm{ml}$ ) and calcofluor white (CW, 5 $\mu \mathrm{M})$. PI-positive cells were counted as dead. Calcofluor white was used to visualize scars on the cell surface (birth scar and bud scars) for replicative age measurements. Cell viability, replicative age, and percent of spores were determined manually using an Olympus BX51 microscope. Photographs were taken with a DP30BW CCD camera. Cell size was measured manually using the ImageJ program.

\section{Statistical analysis}

All data are presented as average and standard error. Wilcoxon signed ranked unpaired test and Kruskal-Wallis test were used to compare datasets from different strains or conditions

\section{REFERENCES}

1. Di Talia S, Wang H, Skotheim JM, Rosebrock AP, Futcher B, and Cross FR (2009). Daughter-specific transcription factors regulate cell size control in budding yeast. PLoS Biol 7(10): e1000221.

2. Bobola N, Jansen RP, Shin TH, and Nasmyth K (1996). Asymmetric accumulation of Ash1p in postanaphase nuclei depends on a myosin and restricts yeast mating-type switching to mother cells. Cell 84(5): 699-709.

3. Sinclair DA and Guarente L (1997). Extrachromosomal rDNA circlesa cause of aging in yeast. Cell 91(7): 1033-1042.

4. Knorre DA, Kulemzina IA, Sorokin MI, Kochmak SA, Bocharova NA, Sokolov SS, and Severin FF (2010). Sir2-dependent daughter-to-mother transport of the damaged proteins in yeast is required to prevent high stress sensitivity of the daughters. Cell Cycle 9(22): 4501-4505.

5. Ashrafi K, Sinclair D, Gordon Jl, and Guarente L (1999). Passage through stationary phase advances replicative aging in Saccharomyces cerevisiae. Proc Natl Acad Sci USA 96(16): 9100-9105.

6. Kennedy BK, Austriaco NR Jr, and Guarente L (1994). Daughter cells of Saccharomyces cerevisiae from old mothers display a reduced life span. J Cell Biol 127(6 Pt 2): 1985-1993. with the R software package. All viability experiments were performed independently 4 times, and each time at least 90 cells were analyzed unless indicated otherwise. When the proportions of the PI-positive cells were low, we counted the age distribution of PI-positive cells only and then extrapolated the result using the average survival in this experiment.

\section{ACKNOWLEDGMENTS}

We are very grateful to Svyatoslav Sokolov, Vitaly Kushnirov, Boris Feniouk, and Peter Kamenski for a valuable discussion of our work. This work was supported by the Russian Foundation for Basic Research grant 12-04-01412-a.

\section{SUPPLEMENTAL MATERIAL}

All supplemental data for this article are available online at www.microbialcell.com.

\section{CONFLICT OF INTEREST}

The authors declare no conflict of interest.

\section{COPYRIGHT}

(C) 2013 Sorokin et al. This is an open-access article released under the terms of the Creative Commons Attribution-NonCommercial-ShareAlike 3.0 license, which allows readers to twist, transform, or build upon the article and then distribute the resulting work non-commercially, as long as they credit you and license their new creations under the identical terms.

Please cite this article as: Maksim I. Sorokin, Dmitry A. Knorre, and Fedor F. Severin (2014). Early manifestations of replicative aging in the yeast Saccharomyces cerevisiae. Microbial Cell 1(1): 37-42. doi: 10.15698/mic2014.01.122

7. Lam YT, Aung-Htut MT, Lim YL, Yang H, and Dawes IW (2011). Changes in reactive oxygen species begin early during replicative aging of Saccharomyces cerevisiae cells. Free Radic Biol Med 50(8): 963-970.

8. McFaline-Figueroa JR, Vevea J, Swayne TC, Zhou C, Liu C, Leung G, Boldogh IR, and Pon LA (2011). Mitochondrial quality control during inheritance is associated with lifespan and mother-daughter age asymmetry in budding yeast. Aging Cell 10(5): 885-895.

9. Klinger $H$, Rinnerthaler $M$, Lam $Y T$, Laun $P$, Heeren $G$, Klocker $A$, Simon-Nobbe B, Dickinson JR, Dawes IW, and Breitenbach M (2010). Quantitation of (a)symmetric inheritance of functional and of oxidatively damaged mitochondrial aconitase in the cell division of old yeast mother cells. Exp Gerontol 45(7-8): 533-542.

10. Lord PG and Wheals AE (1981). Variability in individual cell cycles of Saccharomyces cerevisiae. J Cell Sci 50: 361-376.

11. Westermann B and Neupert W (2000). Mitochondria-targeted green fluorescent proteins: convenient tools for the study of organelle biogenesis in Saccharomyces cerevisiae. Yeast 16(15): 1421-1427.

12. Liu $Z$ and Butow RA (2006). Mitochondrial retrograde signaling. Annu Rev Genet 40: 159-185. 
13. Starovoytova AN, Sorokin MI, Sokolov SS, Severin FF, and Knorre DA (2013). Mitochondrial signaling in Saccharomyces cerevisiae pseudohyphae formation induced by butanol. FEMS Yeast Res 13(4): 367-374.

14. Calvert GR and Dawes IW (1984). Cell size control of development in Saccharomyces cerevisiae. Nature 312(5989): 61-63.

15. Wasko BM and Kaeberlein M (2013). Yeast replicative aging: a paradigm for defining conserved longevity interventions. FEMS Yeast Res: $n / a-n / a$.

16. Pawelec $G$ and Larbi A (2008). Immunity and ageing in man: Annual Review 2006/2007. Exp Gerontol 43(1): 34-38.

17. Coelho M, Dereli A, Haese A, Kühn S, Malinovska L, Desantis ME, Shorter J, Alberti S, Gross T, and Tolić-Nørrelykke IM (2013). Fission Yeast Does Not Age under Favorable Conditions, but Does So after Stress. Curr Biol 23(19): 1844-1852.
18. Balaban NQ, Merrin J, Chait R, Kowalik L, and Leibler S (2004). Bacterial persistence as a phenotypic switch. Science 305(5690): 1622-1625.

19. Allen C, Büttner S, Aragon AD, Thomas JA, Meirelles O, Jaetao JE, Benn D, Ruby SW, Veenhuis M, Madeo F, and Werner-Washburne M (2006). Isolation of quiescent and nonquiescent cells from yeast stationary-phase cultures. J Cell Biol 174(1): 89-100.

20. Aragon AD, Rodriguez AL, Meirelles O, Roy S, Davidson GS, Tapia $\mathrm{PH}$, Allen C, Joe R, Benn D, and Werner-Washburne M (2008). Characterization of differentiated quiescent and nonquiescent cells in yeast stationary-phase cultures. Mol Biol Cell 19(3): 1271-1280.

21. Sherman F (2002). Getting started with yeast. Methods Enzymol 350: 3-41.

22. Severin FF and Hyman AA (2002). Pheromone induces programmed cell death in S. cerevisiae. Curr Biol 12(7): R233-235. 